\title{
ATENUAÇÃO DO RUÍDO DE TRÁFEGO DE VIAS URBANAS PELA V̧EGETAÇÃO EM CURITIBA - PARANÁ, BRASIL
}

\author{
MITIGATION OF URBAN ROAD TRAFFIC NOISE BY VEGETATION IN CURITIBA - \\ PANANÁ, BRAZIL
}

\author{
Jefferson Dias de Oliveira ${ }^{1}$, Daniela Biondi², Antonio Carlos Batista ${ }^{3}$, Allan Rodrigo Nunho dos Reis ${ }^{4}$ \\ Juliane $\mathrm{Nesi}^{5}$
}

\section{RESUMO}

A floresta urbana desempenha inúmeros benefícios às pessoas que vivem em cidades, dentre os quais a amenização do ruído causado pelo tráfego de veículos. Entretanto, pesquisas sobre esse benefício ainda são incipientes no Brasil. O objetivo deste trabalho foi avaliar a vegetação como atenuadora de ruído do tráfego de vias urbanas em áreas verdes de Curitiba - Paraná. A pesquisa foi realizada em dois parques de Curitiba. Utilizando-se dois decibelímetros da marca INSTRUTHERM, modelo DEC-470, em cada local de coleta foram realizadas medições simultâneas, uma na fonte do ruído à margem da avenida e outras em diferentes distâncias a partir da fonte do ruído, com 3 repetições (5 minutos de coleta, e 30 segundos de intervalo). Os resultados mostraram que o local com menor quantidade de vegetação foi o que menos bloqueou o ruído (8,3 dB eq no verão e 7,5 dBeq no inverno), enquanto o local com maior quantidade de vegetação apresentou os maiores valores de atenuação (11,8 dBeq no verão e no inverno). Apesar de haver diferença nos valores médios do bloqueio do ruído entre verão e inverno, não houve diferença estatística significativa, mesmo para as distâncias com presença de árvores caducifólias e semicaducifólias, a qual era esperada essa diferença.

Palavras-chave: Conforto acústico; Floresta urbana; Poluição sonora.

\section{ABSTRACT}

The urban forest has many benefits for people who live in cities, including noise mitigation caused by vehicular traffic. However, research on this benefit is still incipient in Brazil. The aim of this study was to evaluate the vegetation as noise attenuator of urban road traffic in green areas of Curitiba - Paraná. The research was carried out in two parks of Curitiba. Two decibelimeters of the INSTRUTHERM brand, DEC470 model, were used to take simultaneous measurements at each sampling site, one at the source of the noise at the edge of the avenue and others at different distances from the noise source, with 3 repetitions (5 minutes of data collection, and 30 seconds of pause). The results showed that the site with the least amount of vegetation had the least noise mitigation $\left(8.3 \mathrm{~dB}_{\text {eq }}\right.$ in the summer and $7.5 \mathrm{~dB}$ eq in winter), while the site with the highest amount of vegetation had the highest attenuation values $(12 \mathrm{~dB}$ eq in summer and winter). Although there was a difference in mean noise blocking values between summer and winter, there was no significant statistical difference, even for the distances with presence of deciduous and semideciduous trees, which was expected this difference.

Keywords: Acoustic comfort; Urban forest; Sound pollution.

Recebido em 16.02.2018 e aceito em 18.05.2018

1 Engenheiro Florestal. Mestre. Formado pela Universidade Federal do Paraná. Curitiba/PR. E-mail: jeffddo@gmail.com 2 Engenheira Florestal. Doutora. Professora Titular da Universidade Federal do Paraná. Curitiba/PR. E-mail: dbiondi@ufpr.br 3 Engenheiro Florestal. Doutor. Professor Titular da Universidade Federal do Paraná. Curitiba/PR. E-mail: batistaufpr@ufpr.br 4 Engenheiro Florestal. Mestrando do Programa de Pós-graduação em Engenharia Florestal da Universidade Federal do Paraná. Curitiba/PR. E-mail: allannunho@yahoo.com.br

5 Engenheira Florestal. Mestranda do Programa de Pós-graduação em Engenharia Florestal da Universidade Federal do Paraná. Curitiba/PR. E-mail: nesi.juliane@gmail.com 


\section{INTRODUÇÃO}

A poluição do meio ambiente está se tornando cada vez mais severa e generalizada devido ao crescimento da população, urbanização e industrialização das cidades. A migração das pessoas do meio rural para as áreas urbanas, a expansão das cidades, o desenvolvimento de infraestrutura, o crescimento da população e a urbanização são fatores importantes no resultado da mecanização e consequente crescimento dos vários níveis de poluição urbana (ÖNDER; AKAY, 2015).

O sistema de transporte especialmente denso, incluindo estradas, ferrovias e tráfego aéreo, caracterizam o ambiente urbano moderno e causam poluição sonora ambiental. Apesar de ser um tipo menos frequentemente considerado de poluição ambiental, o ruído tem impacto negativo na qualidade de vida das cidades deixando grande parte das populações urbanas vulnerável a problemas de saúde devido ao ruído (ÖNDER; KOCBEKER, 2012). Segundo Van Renterghem e Botteldooren (2012), há aumento de evidências relacionadas aos efeitos negativos para a saúde causada pela exposição continuada ao ruído de tráfego rodoviário. Por consequência, os residentes são forçados a escaparem das estridentes margens das estradas e vias de intenso fluxo de veículos e se refugiarem em pontos mais silenciosos, sendo os parques e bosques os locais mais procurados nos grandes centros, para fugir do estresse causado pela urbanização.

A criação de um ambiente urbano que contribua positivamente para a qualidade de vida tornou-se um grande desafio. Esse ambiente inclui infraestrutura cinza, como estradas e prédios, complementada com infraestrutura verde, especialmente florestas urbanas (OSTOIĆ et al., 2017). Desta forma a vegetação presente nos centros urbanos vem ganhando cada vez mais atenção devido aos benefícios que proporciona, sejam estes ecológicos, estéticos ou sociais (GRISE; BIONDI; ARAKI, 2016; LIVESLEY; ESCOBEDO; MORGENROTH, 2016).

Esta função essencial de promoção da saúde pelos parques urbanos deve ser preservada e melhorada, especialmente porque podem ser acessados facilmente pelos usuários, mas, ao mesmo tempo, são frequentemente cercados por áreas ruidosas devido à emissão sonora do tráfego rodoviário, indústrias e outras fontes (BAMBRILLA et al., 2013).

Nas últimas décadas os estudos que buscam por melhorias da qualidade de vida da população têm se intensificado na perspectiva de buscar a realização de transformações positivas no espaço urbano. Estes estudos visam discutir os problemas inerentes aos centros urbanos de forma a encontrar alternativas para a melhoria da qualidade de vida nas cidades (SOUZA; SOARES, 2017).

Entretanto, mesmo sabendo que a arborização pode trazer diminuição da poluição sonora (EMER et al., 2014; BASSO; CORRÊA, 2014; PORTO; JESUS; PEREIRA JUNIOR, 2017) 
e por consequência a melhoria da qualidade de vida da população, são poucas as pesquisas sobre este assunto no Brasil, principalmente relacionadas com a quantificação e a tipificação da vegetação. Assim, o objetivo deste trabalho foi avaliar a vegetação como atenuadora de ruído do tráfego de vias urbanas em áreas verdes de Curitiba - Paraná.

\section{MATERIAL E MÉTODOS}

\section{Área de estudo}

A presente pesquisa foi desenvolvida no município de Curitiba, localizado no Primeiro Planalto Paranaense (Figura 1), tendo como limites os municípios de Colombo e Almirante Tamandaré, ao norte; Campo Magro, a noroeste; Campo Largo, a oeste; Araucária, a sudoeste; Fazenda Rio Grande, ao sul; São José dos Pinhais, a leste; e Pinhais, a nordeste (INSTITUTO DE PESQUISA E PLANEJAMENTO URBANO DE CURITIBA - IPPUC, 2011). O marco zero da cidade está localizado na Praça Tiradentes, na latitude 25 25'40" Sul e longitude 49 16' $23^{\prime \prime}$ Oeste (IPUCC, 2011).

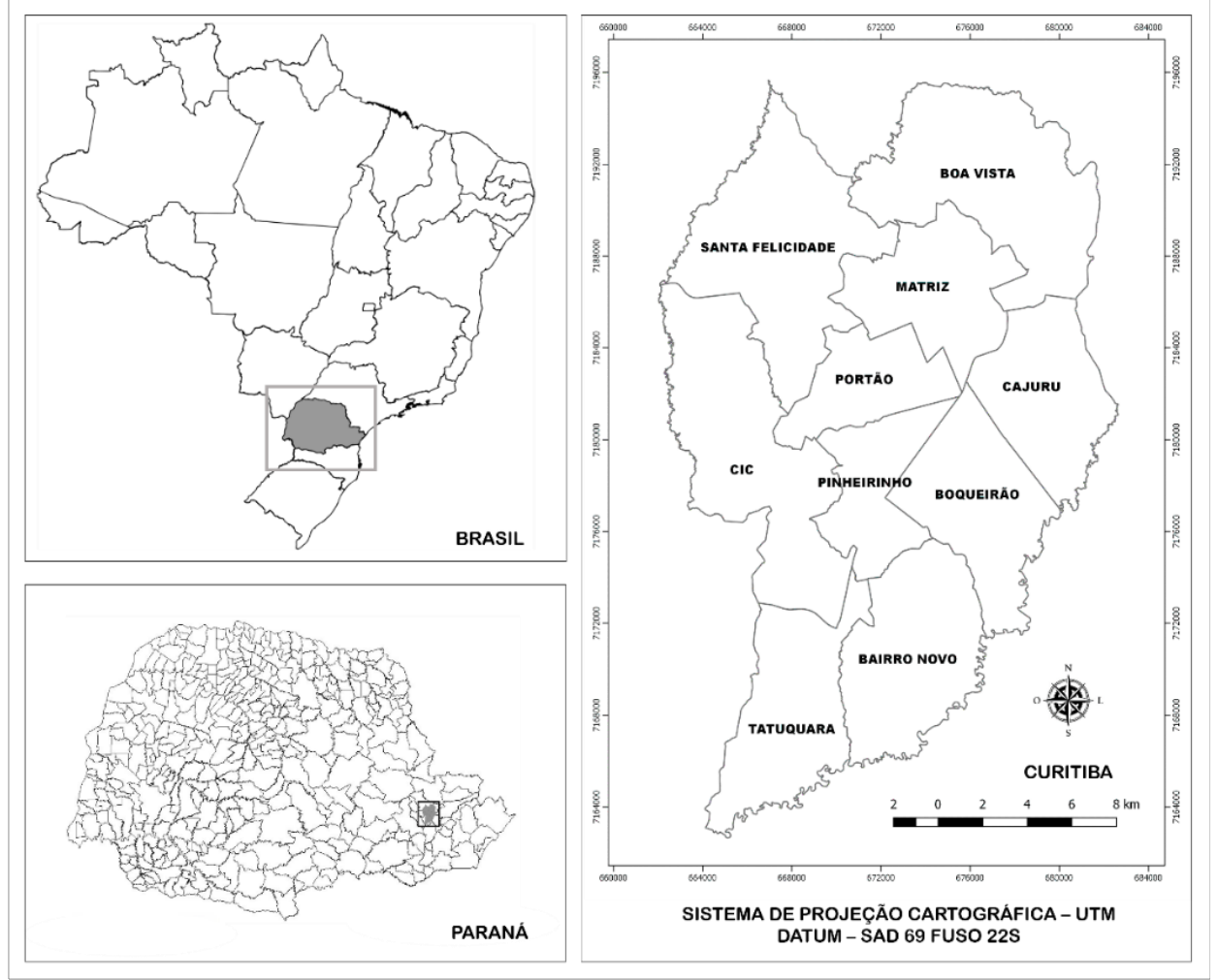

Fonte: O autor (2018)

Figura 1. Localização geográfica da cidade de Curitiba - PR

Figure 1. Geographical location of the city of Curitiba - PR 
Atualmente, a cidade de Curitiba possui mais de 1090 áreas verdes organizadas em eixos de animação, jardinetes, jardins ambientais, largos, núcleos ambientais, praças, bosques, parques e RPPNMs (Reservas Particulares do Patrimônio Natural Municipal) (IPPUC, 2014; IBGE, 2017). Das áreas verdes públicas existentes, foram selecionados os parques que apresentavam uma via de intenso tráfego de veículos e logo em seguida uma faixa de vegetação com no mínimo 60 metros de comprimento e 60 metros de largura. Os valores de comprimento foram definidos para que não houvesse interferência transversal do ruído nos pontos de monitoramento e os valores de largura foram definidos como sendo a totalidade do transecto a ser avaliado. Estes critérios, foram estabelecidos como forma de padronizar os locais de monitoramento e assim compreendendo as condições de estudo na cidade de Curitiba.

$\mathrm{Na}$ definição e seleção das áreas de estudo buscou-se encontrar em Curitiba áreas verdes que se enquadravam nas características desejadas e para isto, foram realizadas expedições a campo e adicionalmente utilizou-se como ferramenta de apoio os dados referentes aos Mapas Temáticos do IPPUC (2011) e o Google Earth. Considerando-se as condições estabelecidas previamente para este estudo, foram selecionadas duas áreas verdes, sendo estas o Jardim Botânico Francisca Maria Garfunkel Rischbieter (dois pontos de monitoramento, sendo o local A na latitude $25^{\circ} 26^{\prime} 26.48^{\prime \prime}$ Sul e longitude 49 $14^{\prime} 23.65^{\prime \prime}$ Oeste; local B na latitude $25^{\circ} 26^{\prime} 38.28 "$ Sul e longitude 49 14' 21.82" Oeste) e o Parque São Lourenço (um ponto de monitoramento, local C, na latitude $25^{\circ} 23^{\prime} 5.64 "$ Sul e longitude $49^{\circ} 16^{\prime} 4.39^{\prime \prime}$ Oeste) as quais estão representados na Figura 2. 


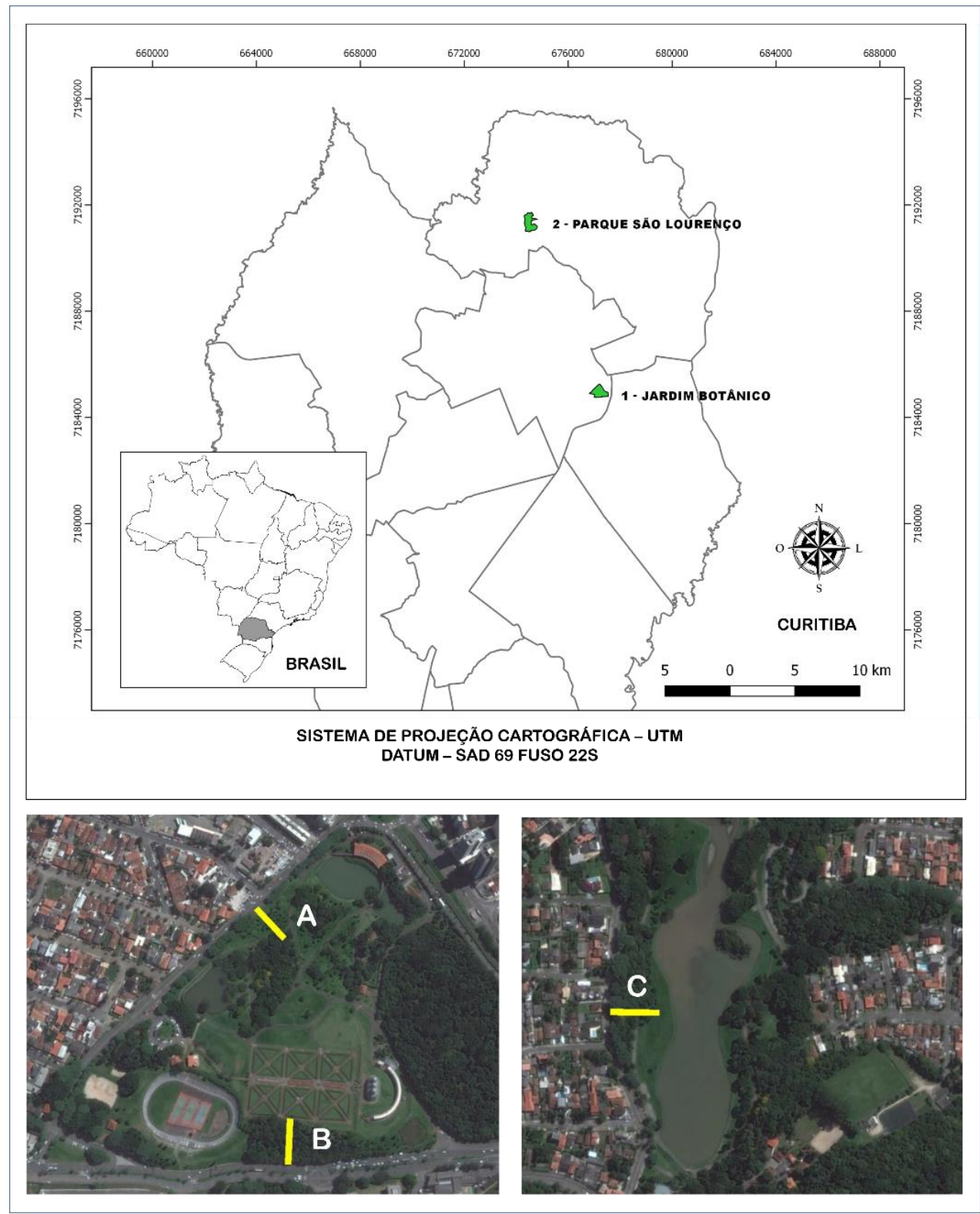

Fonte: O autor (2018)

Figura 2. Áreas verdes de Curitiba-PR inclusas no estudo: 1 - Jardim Botânico; 2 - São Lourenço; A Jardim Botânico sem vegetação; B - Jardim Botânico com vegetação; C - São Lourenço com vegetação

Figure 2. Green areas of Curitiba-PR included in the study: 1 - Botanical Garden; 2 - São Lourenço Park; A - Botanical Garden without vegetation; B - Botanical Garden with vegetation; C - São Lourenço with vegetation

\section{Procedimento de coleta de dados}

Todas as medições foram realizadas em dias úteis da semana, no período de 02 de janeiro a 19 de março e de 21 de junho a 22 de setembro de 2017, compreendendo as estações de verão e inverno respectivamente. As coletas foram realizadas nos horários de pico, das $16 \mathrm{~h}$ 30 às 19h 00, e em dias com condições meteorológicas ausentes de chuva e vento forte, 
seguindo as recomendações da NBR 10151:2000 (ASSOCIAÇÃO BRASILEIRA DE NORMAS TÉCNICAS (ABNT), 2000).

Para avaliar a influência da floresta urbana na amenização do ruído sonoro, foram utilizados dois medidores de pressão sonora/decibelímetros modelo DEC-470 com precisão de $\pm 1,5 \mathrm{~dB}$ e intervalo de medição de $30,0 \mathrm{~dB}(\mathrm{~A})$ a $130,0 \mathrm{~dB}(\mathrm{~A})$. O decibelímetro possui ponderação de frequência $A$ e $C$ com tempo de resposta Fast/Slow (rápida e lenta). Para este estudo o medidor de nível de pressão sonora foi configurado com as especificações apropriadas para medições externas de ruído ambiental, utilizando-se o circuito de compensação em $A$, com ponderação no tempo de resposta lenta S (slow).

A influência do ruído nos diferentes pontos de áreas verdes foi analisada com base nos dados coletados a partir de pontos fixos. Assim, foram definidos três transectos, em seguida foram definidas parcelas de $600 \mathrm{~m}^{2}(10 \mathrm{~m} \mathrm{C} \times 60 \mathrm{~m} \mathrm{~L}$ ) (Figura 3a), onde as distâncias das coletas testadas foram alocadas no meio de cada transecto (5 m) (Figura 3b).

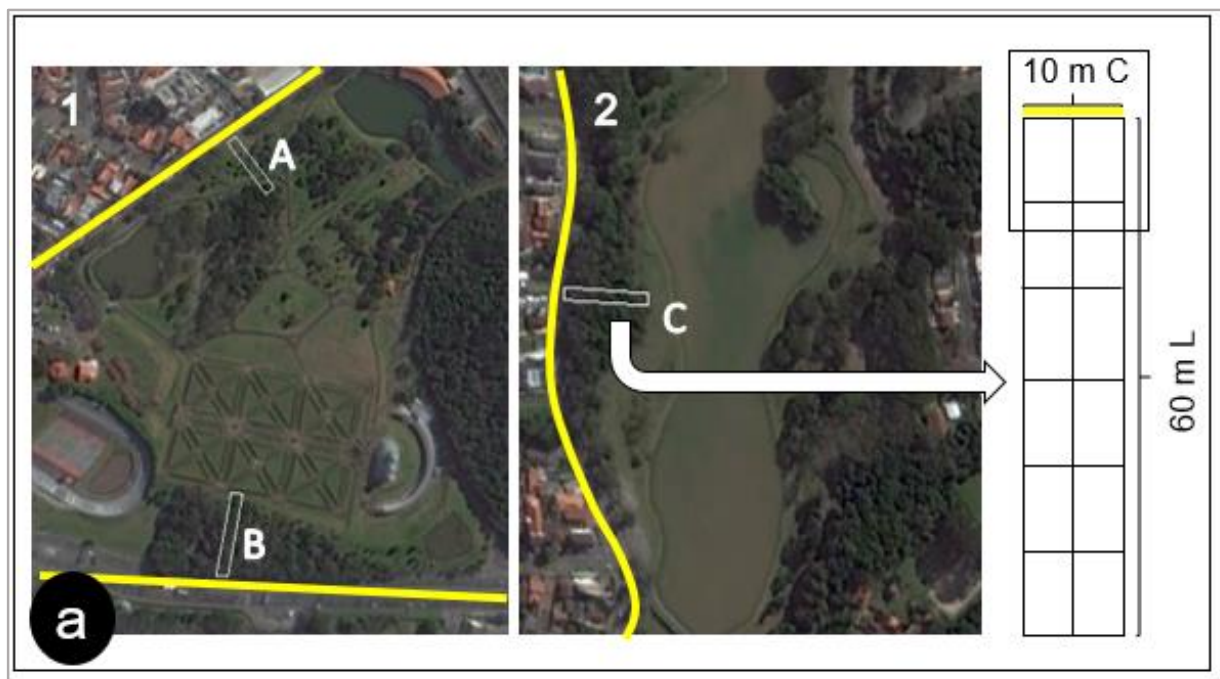

Legenda:

Rua - Fonte do Ruído

Áreas de monitoramento

Copa das árvores

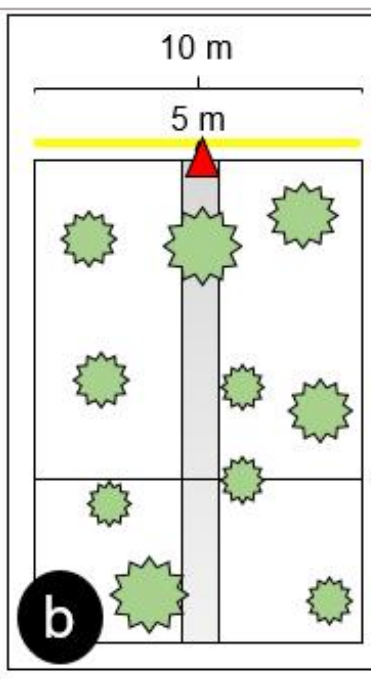

Decibelímetro

Fonte: O autor (2018)

Figura 3. Local do posicionamento dos equipamentos dentro dos transectos: a - Transectos definidos: 1 - Jardim Botânico; 2 - São Lourenço; A - Jardim Botânico sem vegetação; B - Jardim Botânico com vegetação; $C$ - São Lourenço com vegetação; $b$ - Posicionamento dos equipamentos para medição

Figure 3. Place of the positioning of the equipment inside the transects: a - Transects defined: 1 Botanical Garden; 2 - São Lourenço Park; A - Botanical Garden without vegetation; B - Botanic Garden with vegetation; C - São Lourenço with vegetation; b - Positioning of measuring equipment

As distâncias testadas em cada local de coleta foram adaptadas de estudos semelhantes (PATHAK; TRIPATHI; MISHRA, 2008; PUDJOWATI et al., 2013) e foram avaliadas 
em dias diferentes, sendo no primeiro, as distâncias de 0, 10, 20, 3, 40, 50 e 60 metros e no segundo as de $0,5,15,25,35,45$ e 55 metros.

Em cada local de coleta (A, B e C), foram realizadas medições simultâneas em duas condições distintas, uma na fonte do ruído, à margem da avenida, e as outras em diferentes distâncias a partir da fonte (Figura 4), com três repetições (5 mim de coleta, e 30 segundos de intervalo). Para o estudo foi considerado o local A como o local com menor quantidade de vegetação e os locais $\mathrm{B}$ e $\mathrm{C}$ como os locais com nível intermediário e maior quantidade de vegetação respectivamente, para isto foram considerados valores com no mínimo o dobro da quantidade de vegetação da classe anterior.

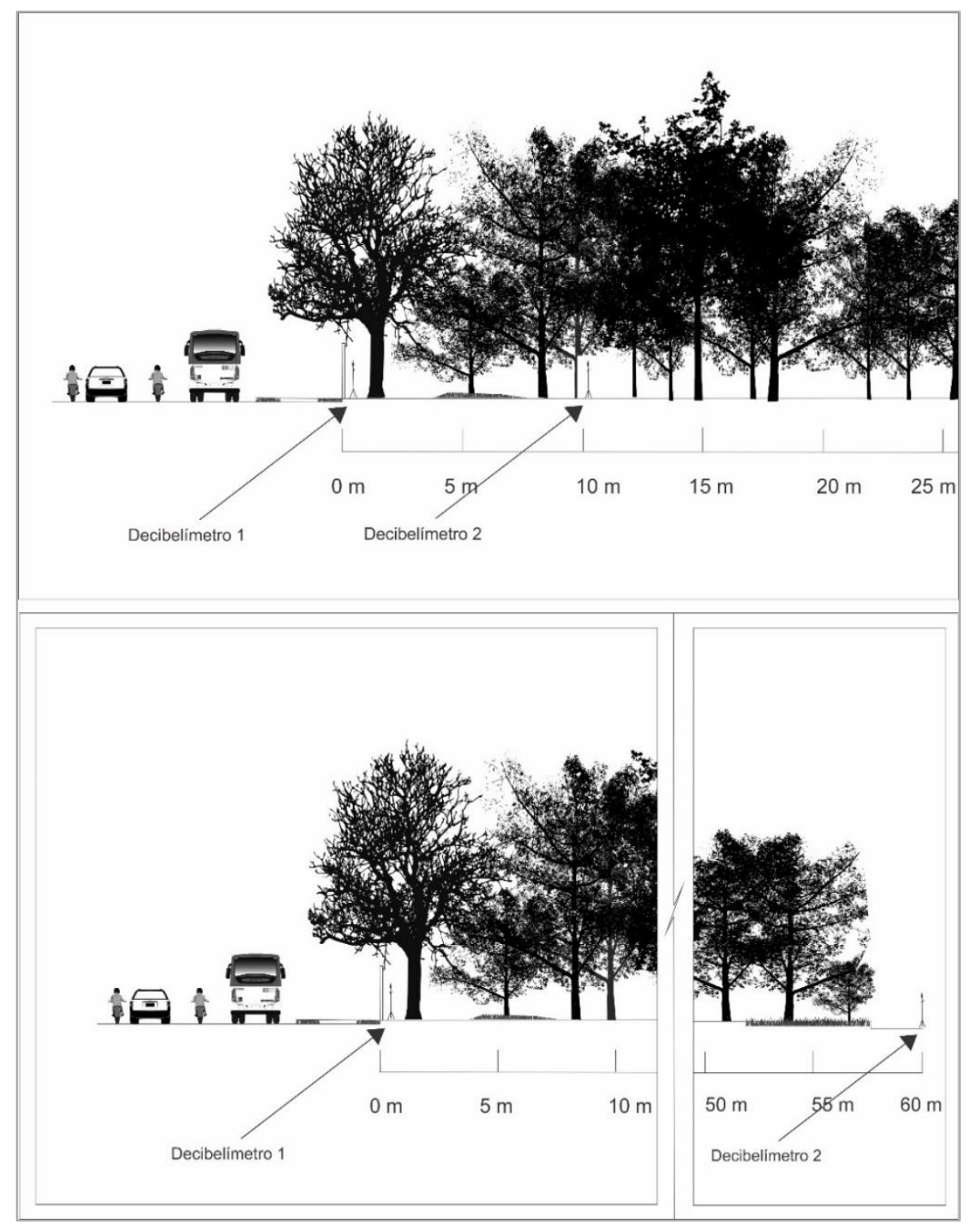

Fonte: O autor (2018)

Figura 4. Esboço da posição dos aparelhos para medição em relação as distâncias e à fonte do ruído com duas medições simultâneas

Figure 4. Sketch of the position of measuring devices in relation to distances and noise source with two simultaneous measurements 
Em cada ponto de medição, os equipamentos foram posicionados a uma altura aproximada de 1,50 m com auxílio de um tripé (PUDJOWATI et al., 2013). Também foram coletados os dados referentes à caracterização dos locais de medição, a partir da parcela retangular de $600 \mathrm{~m}^{2}$, esta foi subdividida em 6 sub-parcelas de $100 \mathrm{~m}^{2}$ cada, as quais foram utilizadas para análise. O tamanho da parcela foi determinado de acordo com o tamanho do transecto, compreendendo a totalidade do mesmo. Nas parcelas, as variáveis coletadas foram tipo de vegetação (exótica ou nativa), número de indivíduos (n), densidade de árvores (n/ha), DAP médio $(\mathrm{cm})$ e altura média $(\mathrm{m})$.

\section{Análise e processamento de dados}

Para a análise e processamento, os dados absolutos provenientes dos decibelímetros foram submetidos à seguinte conversão:

$$
L_{\text {Aeq }}=10 \log \frac{1}{n} \sum_{i=1}^{n} 10^{\frac{L i}{10}}
$$

Em que:

$\mathrm{Li}$ = nível de pressão sonora, em $\mathrm{dB}(\mathrm{A})$, lido em resposta lenta (slow) a cada $5 \mathrm{~s}$, durante o tempo de medição do ruído;

$\mathrm{n}=$ número total de leituras.

Esta conversão foi necessária, pois quando o medidor de nível de pressão sonora não dispõe da função nível de pressão sonora equivalente, $L_{e q}$, o nível de pressão sonora equivalente, $L A_{e q}$, em $d B(A)$, deve ser calculado por meio da expressão recomendada pela NBR 10151:2000 (ABNT, 2000).

Para analisar a influência dos locais com o bloqueio da poluição sonora, foram calculadas as diferenças entre o nível de pressão sonora $\left(\mathrm{dB}_{\mathrm{eq}}\right)$ na distância de 0 metros com as demais distâncias testadas em cada transecto. Os valores máximos e mínimos da pressão sonora de todas as áreas selecionadas também foram determinados para análise dos extremos, bem como para a amplitude de variação.

A análise de variância (ANOVA) foi realizada para avaliar a variação dos resultados para cada distância testada e em seguida a significância da redução de ruído foi calculada com base no teste de comparação de médias de SNK ao nível de $5 \%$ de probabilidade.

As variáveis mensuradas da caracterização das áreas foram correlacionadas com as médias das diferenças em dBL eq. Essa análise foi realizada no software Excel, através da função 
correlação simples para uma média total dos valores em cada distância testada e separados para cada estação.

\section{RESULTADOS E DISCUSSÃO}

Nos três locais de monitoramento a vegetação existente é introduzida, fazendo parte do paisagismo do parque. No entanto, nos locais $A$ e B a vegetação é composta por espécies nativas do Brasil e no local $\mathrm{C}$ composto por espécies nativas e exóticas.

Foram encontradas 12 árvores na área A (Jardim Botânico), sendo assim o local com menor número de indivíduos. O local com maior número de árvores foi o Parque São Lourenço (local C) com 52 árvores e o local B (Jardim Botânico) com número intermediário de indivíduos arbóreos (24). Totalizando 200, 867 e 400 árvores/ha respectivamente. O local C apresentou menor DAP médio $(18,5 \mathrm{~cm})$ e a maior altura média $(9,2 \mathrm{~m})$. Os locais A e B apresentaram DAPs médios bem próximos, com 19,7 e 20,1 cm, respectivamente, e nos locais A e B a altura média encontrada foi de 5,6 e 8,6 metros.

A partir dos dados de ruído coletados, foi possível determinar os valores máximos e mínimos encontrados em cada área de estudo. O nível de poluição sonora máximo registrado na distância zero (fonte de ruído) foi de 101,4 dB (A) no verão e 94,6 dB (A) no inverno, ambos no local $B$. Já o mínimo registrado foi de 49,9 dB (A) no verão e 56,6 dB (A) no inverno, ambos no local C. Já durante toda a coleta de verão, o valor máximo encontrado corresponde ao valor máximo na distância zero (local B - 101,4 dB (A)) e na distância de 25 metros no ponto $C$, foi registrado o menor valor de 47,5 dB $(A)$. No inverno, da mesma forma, o valor máximo encontrado em toda a coleta, corresponde ao valor máximo da distância zero (local B - 94,6 dB (A)), o menor valor registrado também foi encontrado no local $C$, mas na distância de 55 metros, 47,7 dB (A).

A lei municipal $n^{\circ} 10625$ da cidade de Curitiba estabelece como limite máximo o nível de pressão sonora equivalente de 55 decibéis para as áreas verdes no período diurno. Comparando-se esse dado com os encontrados na pesquisa, todos os pontos de monitoramento estão acusticamente poluídos. Szeremeta e Zannin (2009) avaliaram a poluição sonora em alguns pontos no Jardim Botânico e no Parque São Lourenço e também verificaram que estes locais excederam o limite de 55 decibéis estabelecido pela prefeitura.

Além disso, também foi possível determinar a média de decibéis equivalentes $\left(\mathrm{dB}_{\mathrm{eq}}\right)$ bloqueados em cada local de coleta, bem como analisar a diferença entre elas (Tabela 2). 
Tabela 2. Valores médios de decibéis equivalentes $\left(\mathrm{dB}_{\text {eq }}\right)$ bloqueados em cada local de coleta e análise estatística das médias (SNK 95\%)

Table 2. Average values of equivalent decibels $\left(\mathrm{dB}_{\text {eq }}\right)$ blocked at each collection site and statistical analyses (SNK 95\%)

\begin{tabular}{|c|c|c|c|c|c|c|c|}
\hline & \multicolumn{3}{|c|}{ Verão } & \multicolumn{4}{|c|}{ Inverno } \\
\hline Distância (m) & Local A & Local B & Local C & Local A & Local B & Local & \\
\hline 5 & $1,7 \quad b$ & $3,2 a b$ & $5,6 \quad a$ & $1,7 \quad b$ & $4,5 \mathrm{a}$ & 6 & $\bar{a}$ \\
\hline 10 & $2,7 \quad b$ & $5,3 a b$ & $6,3 \mathrm{a}$ & $1,9 \mathrm{~b}$ & $4,8 a$ & 6,4 & a \\
\hline 15 & $6 \quad \mathrm{a}$ & $6,8 a b$ & 8,6 a & $6,8 \quad a$ & $7,7 \quad a$ & 9,7 & a \\
\hline 20 & $8,7 \quad b$ & $8,3 \mathrm{~b}$ & $12,2 \mathrm{a}$ & $6,6 \mathrm{~b}$ & $8,3 a b$ & 10,4 & $a$ \\
\hline 25 & $9,8 \quad b$ & $9 \mathrm{~b}$ & $12,9 \mathrm{a}$ & $8,3 \mathrm{~b}$ & $9,4 \mathrm{~b}$ & 12,4 & $\mathrm{a}$ \\
\hline 30 & 9,6 b & $9,8 \mathrm{~b}$ & $13,2 \mathrm{a}$ & $10,2 a b$ & $8,4 \mathrm{~b}$ & 12,1 & $\mathrm{a}$ \\
\hline 35 & $11,2 a b$ & $9,5 \mathrm{~b}$ & $13,4 \mathrm{a}$ & $10,5 b$ & $9,7 \mathrm{~b}$ & 13,3 & $\mathrm{a}$ \\
\hline 40 & $10,2 b$ & $11,2 b$ & $14,7 \mathrm{a}$ & $8,6 \mathrm{~b}$ & $9,1 \quad b$ & 13,2 & $\mathrm{a}$ \\
\hline 45 & $11,8 \mathrm{a}$ & $14,1 \mathrm{a}$ & $14,1 \mathrm{a}$ & $10,3 \mathrm{~b}$ & $11 b$ & 14 & $\mathrm{a}$ \\
\hline 50 & $10,2 a$ & $10,7 \mathrm{a}$ & $12,9 \mathrm{a}$ & $8,1 \quad b$ & $10 \mathrm{~b}$ & 15,6 & $\mathrm{a}$ \\
\hline 55 & $11,3 a$ & $11,7 \mathrm{a}$ & $14,3 \mathrm{a}$ & $10,6 \mathrm{~b}$ & $10 \mathrm{~b}$ & 14,5 & $\mathrm{a}$ \\
\hline 60 & $8,4 \mathrm{~b}$ & $9,9 \mathrm{~b}$ & $15,5 \mathrm{a}$ & $7,2 \mathrm{~b}$ & $7,8 \mathrm{~b}$ & 14,1 & $\mathrm{a}$ \\
\hline
\end{tabular}

Nota: as médias seguidas pela mesma letra na linha não diferem estatisticamente entre si $(p>0,05)$; Local $A$ - Jardim Botânico sem vegetação; Local B - Jardim Botânico com vegetação; Local C - São Lourenço com vegetação.

Nas distâncias de 5 e 10 metros, houve diferença significativa ao nível de $5 \%$ de probabilidade $(p<0,05)$, apresentando o local $A(1,7 \mathrm{~dB}$ eq no verão e inverno) e $B(3,2$ no verão e 4,5 $\mathrm{dB}_{\text {eq }}$ no inverno) agrupados estatisticamente e o local $C$ com maior quantidade de vegetação com melhor resultado de atenuação do ruído (5,6 no verão e 6 dB eq no inverno).

A distância de 15 metros não apresentou diferença significativa $(p>0,05)$ entre os níveis de vegetação tanto no verão quanto no inverno. Entretanto, o Local $\mathrm{C}$ apresentou os melhores valores de decibéis equivalentes atenuados, sendo 8,6 no verão e 9,4 dB eq no inverno.

As distâncias 20 a 35 metros apresentaram a mesma resposta estatística, significativa ao nível de $5 \%$ de probabilidade $(\mathrm{p}<0,05)$, agrupando os locais A e B (sem diferença) e o local C com maiores médias de atenuação do ruído $\left(12,2 ; 12,9 ; 13,2\right.$ e 13,4 dB $\left.\mathrm{Bq}_{\text {eq }}\right)$ na estação do verão e no inverno $\left(10,4 ; 12,4 ; 12,1\right.$ e $\left.13,3 \mathrm{~dB}_{\text {eq }}\right)$.

$\mathrm{Na}$ distância de 40 metros foi observado diferença significativa, agrupando os locais $\mathrm{A}$ e $B$ (sem diferença) e o local $C$ com maiores médias de atenuação do ruído $(14,7$ dB eq; $p<0,05)$ na estação do verão e no inverno $(13,2 \mathrm{~dB}$ eq; $p<0,01)$.

$\mathrm{Na}$ estação do verão, as distâncias de 45 a 55 metros não obtiveram diferença significativa ( $p>0,05$ ), enquanto que, no inverno, foi observado resposta significativa nas distâncias $45(p<0,05)$ e $50(p<0,01)$ metros, agrupando os locais $A$ e B com a piores médias de atenuação (10,3 e 8,1 (local A); 11,3 e 10,3 dB eq (local B)), enquanto o local C foi observado as maiores médias de atenuação do ruído nestas distâncias, 14 e 15,6 dB eq. A distância de 55 metros apresentou diferença significativa $(p<0,05)$, agrupando os locais A e B com as piores 


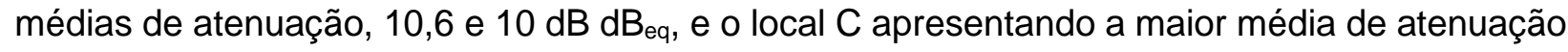
para a distância $\left(14,5 \mathrm{~dB} d B_{\text {eq }}\right)$.

$\mathrm{Na}$ distância de 60 metros ocorreu diferença significativa ao nível de $1 \%$ de probabilidade $(p<0,01)$ tanto no verão quanto no inverno. Os locais de coletas A e B apresentaram as menores médias de atenuação do ruído com 8,4 e 9,9 dB eq no verão e 8,4 e 7,2 e 7,8 dB $\mathrm{B}_{\text {eq }}$ no inverno, enquanto o local $\mathrm{C}$ foi observado $15,5 \mathrm{~dB}_{\text {eq }}$ de atenuação no verão e $14,1 \mathrm{~dB}_{\text {eq }}$ no inverno.

Apesar dos valores de atenuação do ruído em algumas distâncias serem maiores no verão, não foi encontrada diferença estatística nos valores médios de redução do ruído sonoro entre as estações (verão e inverno) (Tabela 3).

Tabela 3. Valores médios de decibéis equivalentes $\left(\mathrm{dB}_{\text {eq }}\right)$ bloqueados em cada estação e análise estatística das médias (SNK 95\%)

Table 3. Average values of equivalent decibels $\left(\mathrm{dB}_{\text {eq }}\right)$ blocked at each season and statistical analyses (SNK 95\%)

\begin{tabular}{cccc}
\cline { 2 - 4 } & \multicolumn{3}{c}{ Local } \\
\cline { 2 - 4 } & $\mathrm{A}$ & $\mathrm{B}$ & $\mathrm{C}$ \\
\hline Verão & $8,5 \mathrm{a}$ & $9,2 \mathrm{a}$ & $12,0 \mathrm{a}$ \\
Inverno & $7,1 \mathrm{a}$ & $8,4 \mathrm{a}$ & $11,8 \mathrm{a}$
\end{tabular}

Nota: as médias seguidas pela mesma letra não diferem estatisticamente entre si ( $p>0,05)$; - Jardim Botânico sem vegetação; B - Jardim Botânico com vegetação; C - São Lourenço com vegetação.

Em um estudo realizado em Teerã no Irã, Maleki e Hosseini (2011) analisaram o efeito da folhagem das árvores sobre a redução do ruído no verão (quando as árvores estão cobertas com folhas) e no inverno (quando perdem suas folhas), observando mudanças significativas ( $p$ $<0,05)$ na atenuação da poluição sonora causada por diferentes espécies na distância de 100 metros da fonte de ruído. Com a espécie Robinia pseudoacasia L. no verão foram encontrados 14,7 dB $\mathrm{dB}_{\text {eq }}$ e no inverno 9,7 com uma diferença de $5 \mathrm{~dB}_{\text {eq }}$ entre o verão e inverno. Já para um padrão misto de $R$. pseudoacasia e Pinus eldarica Medw, encontraram uma diferença maior, de $6,1 \mathrm{~dB}_{\text {eq }}$ entre a estação de verão e inverno. Essa diferença pode estar associada á localização do estudo citado, hemisfério norte, onde as estações de verão e inverno são bem distintas. Além disso, as espécies estudadas são diferentes das ocorrentes nos locais de monitoramento (pouca frequência de espécies caducifólias). Esses componentes reduzem o ruído na estação verde quando as árvores possuem mais ramos e folhas.

Em estudos semelhantes na cidade de Fukuoka no Japão, Fujiwara, Hothersall e Kim (1998) verificaram que uma faixa de árvores com uma largura de 30 metros resultou em mais 8 dB de atenuação do que a mesma largura de terra sem árvores. Já Ow e Ghosh (2017) avaliaram o efeito da vegetação sobre a redução do ruído do tráfego rodoviário sob diferentes intensidades de plantio em um parque de Singapura. Os resultados mostraram que o ruído do trânsito foi 
reduzido em $50 \%$ quando a vegetação foi aumentada de uma intensidade de plantio mínima a moderada, e em média, as barreiras vegetativas (moderadas a densas) conseguiram reduzir o ruído do tráfego em 9-11 dB.

O local de monitoramento A apresentou diferença estatística com valores inferiores de decibéis bloqueados em todas as distâncias testadas, já o local com maior quantidade de vegetação (local C) apresentou os maiores valores de atenuação do ruído. Este resultado pode ser devido as plantas e as árvores atuarem na poluição sonora através da absorção, desvio, reflexão e refração das ondas sonoras (AYLOR, 1972; KRAGH, 1981; VAN RENTERGHEM, 2014).

A correlação entre os valores médios de decibéis bloqueados e os valores de densidade da vegetação e número de indivíduos nos três pontos analisados resultou uma correlação positiva muito forte de 0,99, assim é possível afirmar que, quanto mais vegetação, mais o ruído será bloqueado por esta vegetação. O DAP médio das árvores $(-0,91)$ apresentou correlação negativa forte. Isto ocorre, porque, os troncos das árvores fazem a reflexão, difração/blindagem e espalhamento do som (VAN RENTERGHEM, 2014) servindo como bloqueio nos primeiros metros acima do solo $(1,5 \mathrm{~m})$, dificultando o livre deslocamento do som até o receptor. Foi observado coeficiente de correlação positiva forte $(0,76)$ entre a altura média das árvores e os valores de decibéis reduzidos, demostrando a importância da vegetação no bloqueio do ruído. Além disso, Aylor (1972) reforça que a menor visibilidade e a maior quantidade de vegetação entre o ruído e o receptor, há melhores resultados sobre a redução da poluição sonora.

\section{CONCLUSÕES}

A vegetação se mostrou eficiente no bloqueio do ruído e a combinação de fatores, incluindo forma e tamanho dos fragmentos de vegetação, influenciaram na propagação do ruído sonoro. O local com menor quantidade de vegetação, obteve os menores valores de amenização do ruído, enquanto que o local com maior quantidade de vegetação conseguiu bloquear o ruído em 15,5 dB eq no verão e $15,6 \mathrm{~dB}_{\text {eq }}$ no inverno.

Apesar da diferença nos valores médios do bloqueio do ruído entre verão e inverno, não houve diferença estatística significativa, mesmo para as distâncias com presença de árvores caducifólias e semi-caducifólias, a qual era esperada essa diferença.

Os resultados demonstraram que a vegetação presente nas áreas de estudo proporciona um isolamento acústico expressivo, o que realça importância de áreas verdes com faixas de vegetação próximas às vias de intenso fluxo de veículos. 


\section{REFERÊNCIAS}

ASSOCIAÇÃO BRASILEIRA DE NORMAS TÉCNICAS (ABNT). NBR 10151:2000. Acústica Avaliação do ruído em áreas habitadas, visando o conforto da comunidade - Procedimento. Disponível em: <http://www.semace.ce.gov.br/wp-content/uploads/2012/01/Avalia\%C3\%A7\% C3\%A3o+do+Ru\%C3\%ADdo+em+\%C3\%81reas+Habitadas.pdf>. Acesso em: 20 nov 2016.

AYLOR, D. E. Noise reduction by vegetation and ground. Journal of the Acoustical Society of America, New York, v. 51, p. 197-205, 1972.

BASSO, J. M.; CORRÊA, R. S. Arborização urbana e qualificação da paisagem. Paisagem e Ambiente, São Paulo, n. 34, p. 129-148, 2014.

BRAMBILLA, G.; GALLO, V.; ASDRUBALIA, F.; D'ALESSANDRO, F. The perceived quality of soundscape in three urban parks in Rome. Journal of the Acoustical Society of America, New York, v. 134, n. 1, p. 832-839, 2013.

EMER, A. A.; CADORIN, D. A.; SILVA, L.; MELLO, N. A. Arborização dos bairros Veneza e Aeroporto em Pato Branco - PR. Revista da Sociedade Brasileira de Arborização Urbana, Piracicaba, v. 9, n. 2, p. 88-100, 2014.

FUJIWARA, K.; HOTHERSALL, D. C.; KIM, C. H. Noise barriers with reactive surfaces. Applied Acoustics, Great Yarmouth, v. 53, n. 4, p. 255-72, 1998.

GRISE, M. M.; BIONDI, D.; ARAKI, H. A Floresta Urbana da cidade de Curitiba, PR. Revista Floresta, Curitiba, v. 46, n. 4, p. 425-437, 2016.

INSTITUTO BRASILEIRO DE GEOGRAFIA E ESTATÍSTICA (IBGE). Censo demográfico. Brasil. 2010. Disponível em <http://www.ibge.gov.br/> Acesso em: 13 abr. 2016.

INSTITUTO DE PESQUISA E PLANEJAMENTO URBANO DE CURITIBA (IPPUC). Desenvolvimento sustentável: indicadores de sustentabilidade de Curitiba - 2010. Curitiba: IPPUC, 2011.

INSTITUTO DE PESQUISA E PLANEJAMENTO URBANO DE CURITIBA (IPPUC). Curitiba em dados. Curitiba, 2014. Disponível em: <http://curitibaemdados.ippuc.org.br/>. Acesso em: 13 abr. 2016.

KRAGH, J. Road traffic noise attenuation by belt of trees. Journal of Sound and Vibration, Amsterdam, v. 74, n. 2, p. 235-241, 1981.

LIVESLEY, S. J.; ESCOBEDO, F. J.; MORGENROTH, J. The biodiversity of urban and periurban forests and the diverse ecosystem services they provide as socio-ecological systems.

Forests, Basel, v. 7, n. 12, p. 10-14, 2016.

MALEKI, K.; HOSSEINI, S. M. Investigation of the effects of leaves, branches and canopies of trees on noise pollution reduction. Annals of Environmental Science, Boston, v. 5, p. 13-21, 2011.

ÖNDER, S.; AKAY, A. Reduction of traffic noise pollution effects by using vegetation, Turkey' sample. Statewide Agricultural Land Use Baseline, Honolulu, v. 1, p. 74-86, 2015. 
ÖNDER, S.; KOCBEKER, Z. Importance of the green belts to reduce noise pollution and determination of roadside noise reduction effectiveness of bushes in Konya, Turkey.

International Science Index, Dubai, v. 6, n. 6, p. 373-376, 2012.

OSTOIĆ, S. K. et al. Citizen's perception of and satisfaction with urban forests and green space: results from selected southeast european cities. Urban Forestry \& Urban Greening, Amsterdam, v. 23, p. 93-103, 2017.

OW, L. F.; GHOSH, S. Urban cities and road traffic noise: reduction through vegetation. Applied Acoustics, Great Yarmouth, v. 120, p. 15-20, 2017.

PATHAK, V.; TRIPATHI, B. D.; MISHRA, V. K.; Dynamics of traffic noise in a tropical city Varanasi and its abatement through vegetation. Environmental Monitoring and Assessment, Bangor, v. 146, p. 67-75, 2008.

PORTO, M. L.; JESUS, E. S.; PEREIRA JUNIOR, A. Análise das tendências nas relações entre fluxo de veículos, arborização e os níveis de intensidade de ruído. Ecologia e Nutrição Florestal, Santa Maria, v. 5, n. 3, p. 87-97, 2017.

PUDJOWATI, U. R.; YANUWIYADI, B.; SULISTIONO, R.; SUYADI. Estimation of noise reduction by different vegetation type as a noise barrier: a survey in highway along Waru Sidoarjo in East Java, Indonesia. International Journal of Engineering and Science, Amsterdam, v. 2, n. 11, p. 20-25, 2013.

SOUZA, J. R.; SOARES, B. R. Em busca de cidades saudáveis: metodologia de análise de indicadores ambientais urbanos em Uberlândia, Minas Gerais. Fórum Ambiental da Alta Paulista, São Paulo, v. 13, n. 1, p. 141-157, 2017.

SZEREMETA, B.; ZANNIN, P. H. T. Analysis and evaluation of soundscapes in public parks through interviews and measurement of noise. Science of the Total Environment, Amsterdam, v. 407, p. 6143-6149, 2009.

VAN RENTERGHEM, T.; BOTTELDOOREN, D. On the choice between walls and berms for road traffic noise shielding including wind effects. Landscape and Urban Planning, Amsterdam, v. 105, p. 199-210, 2012.

VAN RENTERGHEM, T. Guidelines for optimizing road traffic noise shielding by non-deep tree belts. Ecological Engineering, Amsterdam, v. 69, p. 276-286, 2014. 